\title{
Improving android-based e-learning skills of Biology teachers in Enrekang Regency, South Sulawesi
}

\author{
Arifah Novia Arifin ${ }^{\text {a,1, }}{ }^{*}$, Arsad Bahri ${ }^{a, 2}$, A. Irma Suryani ${ }^{\text {a,3 }}$ \\ ${ }^{a}$ Department of Biology, Faculty of Mathematics and Natural Sciences, Universitas Negeri Makassar, Jl. Daeng Tata Raya, Parang Tambung, Makassar, \\ South Sulawesi 90224, Indonesia \\ ${ }^{1}$ arifahnoviaarifin@unm.ac.id*,2arsadbahri@unm.ac.id, ${ }^{3}$ a.irma.suryani@unm.ac.iid \\ * Corresponding author
}

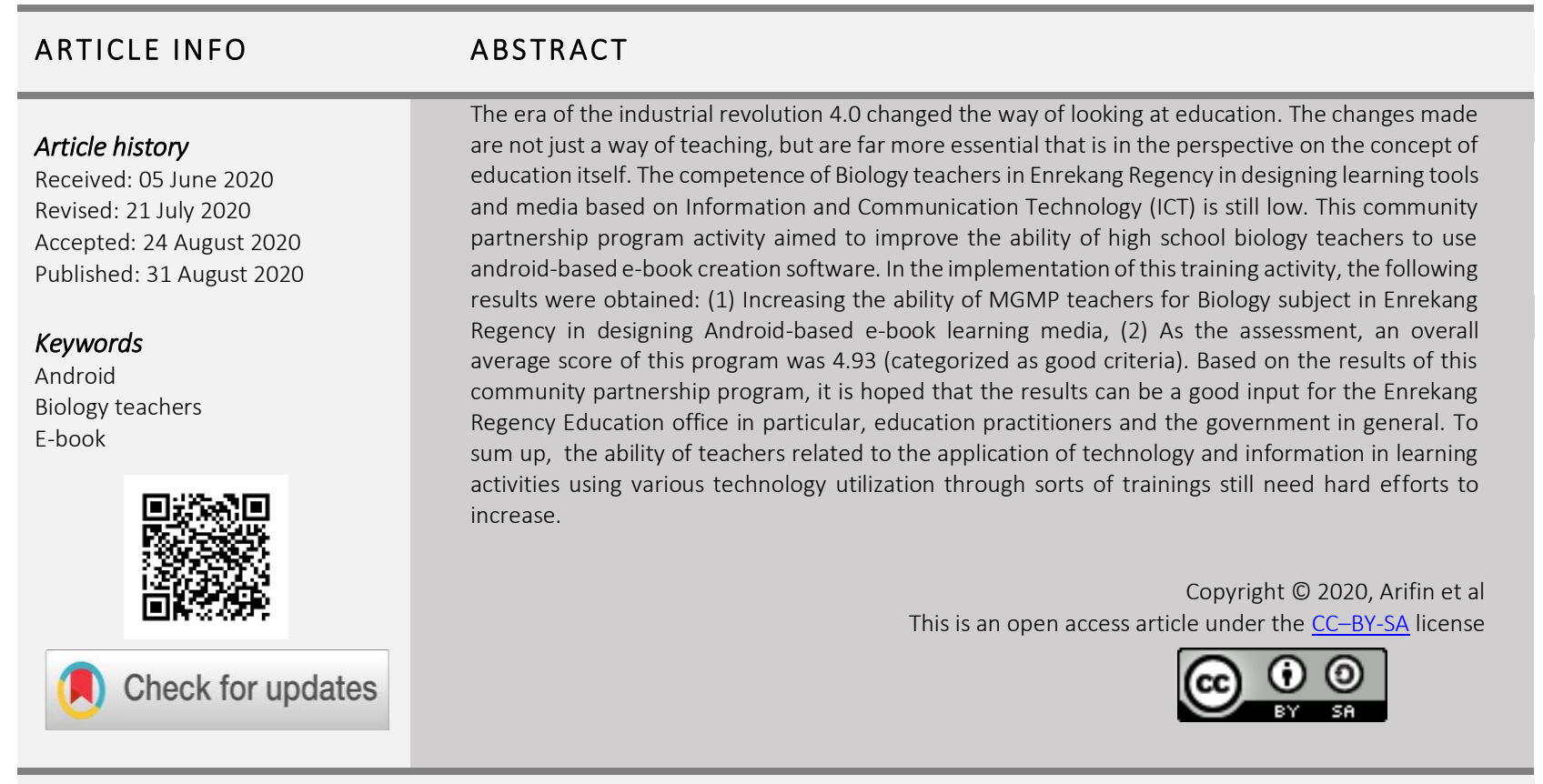

How to cite: Arifin, A. N., Bahri, A., \& Suryani, A. I. (2020). Improving android-based e-learning skills of Biology teachers in Enrekang Regency, South Sulawesi. Journal of Community Service and Empowerment, 1(2), 80-85. doi: https://doi.org/10.22219/jcse.v1i2.12418

\section{PENDAHULUAN}

Salah satu penanda perkembangan peradaban manusia ialah perkembangan teknologi. Perkembangan itu tentunya akan mempengaruhi berbagai macam unsur dalam kehidupan manusia, salah satunya ialah dunia pendidikan (Taguma, Feron, \& Lim, 2018). Keterampilan yang harus dimiliki pada abad ke-21 adalah life and career skills, learning and innovation skills, dan information media and technology skills (Anagün, 2018; Trilling \& Fadel, 2009; Zalsalina, Palupi, \& Riyaningsih, 2020). Era revolusi industri 4.0 mengubah cara pandang tentang pendidikan. Pengaruh itu dapat terlihat dari berbagai perbedaan yang nampak dari kegiatan belajar mengajar era digital saat ini dengan masa lalu (Afrianto, 2018; Oke \& Fernandes, 2020; Sharma, 2019). Misalnya, dulu, untuk mengakses informasi, siswa hanya bisa mengaksesnya melalui buku, media cetak seperti koran dan majalah, dan tentu saja guru. Sedangkan kini, siswa dapat dengan mudah mengakses informasi melalui Smartphone dan media online lainnya, yang dikenal dengan e-learning (Irodah et al., 2020).

Perkembangan teknologi serta adaptasi terhadap perkembangan teknologi itu merupakan salah satu fokus Sustainable Development Goals (SDGs). Dalam laporannya yang berjudul "A New Global Partnership: Erdicte Poverty and Transform Economies through Sustainable Development", HLPEP mengusulkan 12 tujuan dengan 54 target pembangunan pasca-2015. Pada poin ke-12, yaitu "menciptakan lingkungan hidup dan katalisator pembiayaan jangka panjang secara global", terdapat penjabaran "Mempromosikan kolaborasi dan akses terhadap ilmu pengetahuan, teknologi, inovasi, dan data pembangunan" (Badan Pusat Statistik, 2014). Oleh karena itu, pemanfaatan ICT oleh penduduk usia muda harus ditingkatkan (Alisjahbana et al., 2018). Kenyataannya, maish banyak kegiatan pembelajaran, 
termasuk pembelajaran biologi yang belum mengintegrasikan dengan pentingnya penguasaan media Informasi digital (internet, multimedia, E-learning) ata penggunaan ICT (Restiyani, Juanengsih, \& Herlanti, 2015; Ritonga, 2017).

Sehubungan dengan itu, Musyawarah Guru Mata Pelajaran (MGMP) Biologi SMA Kabupaten Enrekang, merupakan salah satu MGMP yang aktif hingga saat ini. Ada sejumlah program yang telah dilaksanakan dalam beberapa tahun terakhir ini, diantaranya melaksanakan pertemuan rutin yang membahas tentang masalah-masalah yang di hadapi guru di lapangan, kegiatan pendidikan dan pelatihan, workshop, seminar, simposium dan sejumlah kegiatan ilmiah lainnya dalam meningkatkan profesionalisme sebagai guru. Kegiatan tersebut tentunya memberikan dampak yang positif terhadap peningkatan kompetensi profesional Guru Biologi SMA Kabupaten Enrekang, akan tetapi dalam hal tertentu mereka merasa masih perlu meningkatkan skill mereka dalam pembuatan perangkat dan media pembelajaran berbasis berbasis Information and comunication tecnology (ICT).

Hasil wawancara dengan guru-guru Guru Biologi SMA Kabupaten Enrekang, dijumpai sejumlah informasi, antara lain: 1) saat ini hampir semua siswa dan guru memiliki smartphone android/ios, tablet android/ios dan perangkat komputer, sehingga sangat memudahkan nantinya dalam menggunakan e-book yang dibuat. 2) Penggunaan e-book di era kecepatan saat ini memudahkan untuk memperoleh informasi tambahan. 3) E-book yang ada saat ini hanya peralihan dari buku cetak ke buku digital, oleh karena itu perlu adanya e-book yang tidak memuat gambar-gambar saja, melainkan perlu adanya penambahan multimedia untuk memeprmudah siswa memahami konsep.

Sejumlah guru Biologi masih sedikit yang mengenal e-book dan software yang terkait pembuatan e-book berbasis android ini. Selain itu sejumlah informasi yang bersumber dari internet masih perlu diolah dan dikelola secara profesional sehingga menjadi layak untuk digunakan di kelas sesuai dengan kompetensi pembelajaran yang diinginkan sehingga menjadi sumber belajar bagi siswa. Solusi yang ditawarkan: memberikan pengetahuan kepada guru dalam menggunakan software e-book berbasis android, dan melatihkakan guru dalam membuat e-book yang menjadi satu dengan multimedia interaktif dan memanfaatkannya sebagai perangkat pembelajaran yang sifatnya mobile.

Beberapa hasil penelitian terkait pengembangan media pembelajaran e-book yang telah dilakukan, di antaranya Darlen, Sjarkawi, dan Lukman (2015) menunjukkan bahwa pengembangan e-book interaktif untuk pembelajaran fisika SMP telah diuji kelayakan, kemenarikan dan keefektifan dan dinyatakan valid. Adnan, Muharram, dan Jihadi (2019) melaporkan bahwa e-book biologi konstruktivistik yang dikembangkan memenuhi kriteria kevalidan, kepraktisan, dan efektif dalam meningkatkan motivasi belajar siswa hal ini ditandai dengan meningkatnya aspek perhatian, relevansi, keyakinan dan kepuasan sebagai faktor persepsional motivasi. Penelitian yang sama juga dilakukan oleh Suryani dan Sukarmin (2012) dan Restiyowati dan Sanjaya (2012). Hasil penelitian Kusumastuti (2020), terkait pengaruh integrasi $e$ book interaktif pada kegiatan belajar mengajar sains menunjukkan bahwa setiap kelas menunjukkan perbedaan hasil belajar yang signifikan, dimana kelas eksperimen lebih baik daripada kelas kontrol. Temuan ini juga didukung oleh hasil angket bahwa siswa kelas eksperimen memiliki pengalaman belajar yang lebih baik daripada siswa kelas kontrol. Hal yang sama juga diperoleh dari hasil penelitian Soulissa, Smith, dan Matdoan (2020), terdapat hubungan yang sangat kuat dan signifikan antara bahan ajar berbasis android e-book dan berpikir kritis secara bersama-sama terhadap hasil belajar konsep sistem pernapasan manusia dengan nilai korelasi ( $r$ ) sebesar 0,971. Budiarti, Handhika, dan Kartikawati (2017) juga mengemukakan ada pengaruh penerapan media pembelajaran E-book dengan pendekatan scientific untuk meningkatkan hasil belajar siswa pada mata pelajaran Rangkaian Induktor. Hardiansyah (2016) membuktikan bahwa media pembelajaran Flash Flipbook efektif untuk meningkatkan hasil belajar siswa pada mata pelajaran perakitan komputer Kelas X TKJ SMK Negeri 7 Surabaya. Hasil penelitian Hakim dan Hasbiyati (2018) memanfaatkan smartphone sebagai media dalam menunjang proses pembelajaran, diperoleh hasil media E-Book berekstensi EPUB dapat meningkatkan aktivitas dan hasil belajar siswa.

Salah satu hasil program pengabdian yang telah dilakukan oleh Hala dan Arifin (2019) yaitu Guru-guru IPA SMP di Kabupaten Gowa telah mampu menghasilkan sumber belajar digital seluler yang inovatif dan mobile menggunakan perangkat lunak e-book berbasis Android, majalah elektronik, dan pembuat kuis. Sumber belajar yang dihasilkan dapat digunakan sebagai media pembelajaran blended yang dapat diakses di ponsel berbasis Android. Dengan demikian, dapat membantu guru dan siswa dalam proses pembelajaran. Kegiatan program kemitraan masyarakat ini merupakan bentuk peran aktif perguruan tinggi untuk meningkatkan kemampuan guru dalam memanfaatkan kemampuan TPACK yang diharapkan akan berdampak pada kualitas pembelajaran dan kualitas siswa lulusan.

Sebagaimana menurut Ariyana (2018), kesenjangan penguasaan teknologi informasi bagi guru-guru di daerah dengan guru-guru dari kota-kota besar dapat diperkecil. TPACK adalah salah satu framework yang mengintegrasikan antaran pengetahuan Teknologi (Technological Knowledge), pengetahuan Pedagogi (Pedagogy Knowledge), dan pengetahuan Konten (Content Knowledge) dalam sebuah konteks pembelajaran. TPACK awalnya dikembangkan oleh Shulman's (1987, 1986) yang mendeskripsikan tentang Pedagogical and Content Knowledge (PCK) dan menggambarkan bagaimana pemahaman guru terhadap teknologi pembelajaran dan dihubungkan dengan PCK dan lainnya, agar menghasilkan pembelajaran yang efektif menggunakan teknologi. Kegiatan program kemitraan masyarakat ini bertujuan untuk meningkatkan kemampuan guru biologi SMA dalam menggunakan software pembuatan e-book berbasis android. 


\section{METODE}

Pelaksanaan kegiatan program kemitraan masyarakat ini ditujukan kepada guru-guru biologi yang tergabung dalam MGMP Biologi Kabupaten Enrekang dengan memberikan pemahamanan dan memberdayakan guru-guru dalam hal meningkatkan wawasan, pengetahuan, kemampuan, keterampilan dalam memanfaatkan aplikasi media pembelajaran elearning menggunakan software android e-magazine. Kegiatan ini berlangsung pada tanggal 19-21 Juli 2019 bertempat di Aula Gedung Dinas Pendidikan Kabupaten Enrekang, Sulawesi Selatan. Langkah-langkah pelaksanaan kegimeliputi: (1) Tahap Persiapan, merupakan kegiatan sebelum pelaksanaan PKM yang meliputi sosialisasi mengenai kegiatan PKM yang akan dilaksanakan, melakukan studi pendahuluan, serta berkoordinasi dengan MGMP Biologi dan Dinas Pendidikan Kabupaten Enrekang sebagai mitra untuk pelaksanaan PKM. Dilanjutkan dengan studi pendahuluan untuk memperoleh gambaran awal kondisi mitra PKM. (2) Tahap pelaksanaan, meliputi (a) pembukaan oleh Dinas Kabupaten Pendidikan Kabupaten Enrekang, (b) pemberian materi terkait software aplikasi android e-magazine, (c) instalasi software pada perangkat laptop, (d) memberikan handout petunjuk pengoprasian software, (e) melakukan demo terkait penggunaan aplikasi, (d) proses pemindahan aplikasi ke handphone android, (e) ujicoba aplikasi android e-magazine pada masingmasing peserta serta melakukan tanya jawab dengan peserta untuk menyelesaikan permasalahan yang dihadapi dalam menggunakan aplikasi e-book berbasis android magazine. (3) Tahap monitoring dan evaluasi program, pada bagian akhir kegiatan ini peserta melakukan proses penilaian terkait pelaksanaan kegiatan program kemitraan masyarakat ini. Pengumpulan data terkait ketercapaian pelaksanaan kegiatan ini dilakukan dengan melakukan observasi kepada peserta pelatihan dan pemberian lembar penilaian proses kegiatan kepada peserta. Data kemudian dianalisis dengan menghitung nilai rata-rata dari setiap item kegiatan yang diisi oleh setiap peserta. Kemudian diakumulasi dan kembali dirata-ratakan, sehingga diperoleh nilai akhir terkait pelaksanaan kegiatan ini.

\section{HASIL DAN PEMBAHASAN}

Kegiatan program kemitraan masyarakat yang dilaksanakan di Kabupaten Enrekang yang bermitra dengan guru MGMP Biologi, diberikan materi mengenal e-book dan software yang terkait pembuatan e-book berbasis android. Materi ini diberikan untuk meningkatkan kemampuan para guru-guru Biologi untuk menghadapi perkembangan informasi dan teknologi di sektor pendidikan. Materi yang disampaikan pada kegiatan pengabdian masyarakat oleh tim pengabdi adalah sebagai berikut; (a) Konsep Aplikasi E-book berbasis Android. (b) Instal software Android Magazine. (c) Pengenalan Tools dalam Android Magazine. (d) Praktek menggunakan Android Magazine. (e) Tanya jawab dan diskusi. Dokumentasi kegiatan sebagaimana disajikan pada Gambar 1. Terlihat suasana pendampingan dan pelatihan yang dilakukan oleh tim pengabdi kepada guru-guru.

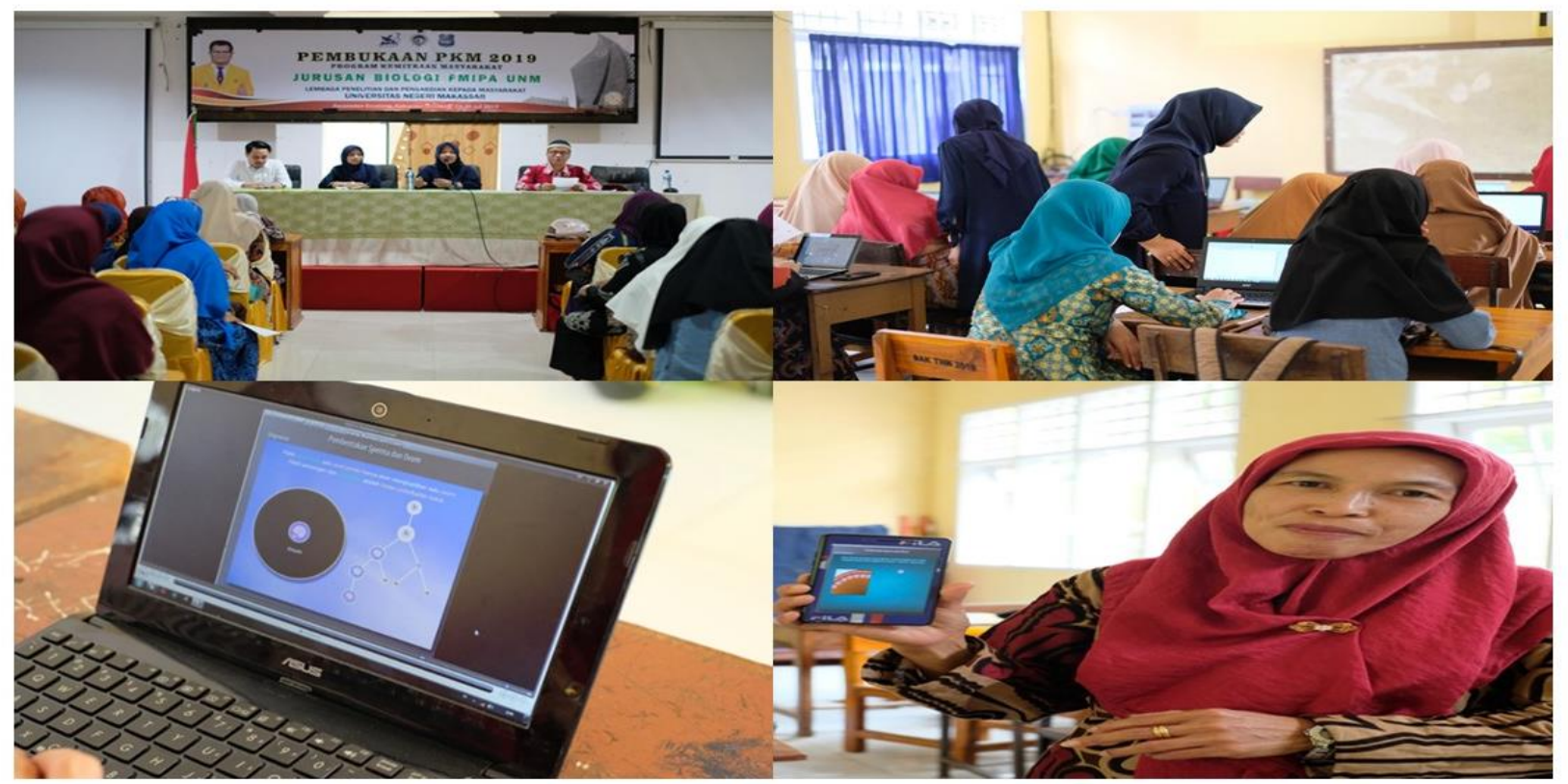

Gambar 1. Pelaksanaan kegiatan program kemitraan masyarakat guru-guru MGMP Biologi di Dinas Pendidikan Kabupaten Enrekang

Hasil analisis penilaian pelaksanaan kegiatan program kemitraan masyarakat oleh peserta menunjukkan beberapa poin, yaitu materi yang disampaikan dalam kegiatan memperoleh skor 4,9 pada kriteria baik. Respon masyarakat memperoleh skor 4,8 pada kriteria baik. Hubungan materi yang disajikan dengan kebutuhan masyarakat dengan skor 5,8 kriteria baik sekali. Keterkaitan antara materi dengan aplikasi yang dapat diserap di masyarakat skor 4,7 kategori baik. 
Keterkaitan materi dengan kebutuhan 4,9 kategori baik. Pemateri dan teknik penyajian skor 4,8 kriteria baik. Waktu yang digunakan dalam pemberi materi dengan skor 4,6 kriteria baik. Kejelasan materi skor 4,9 kriteria baik. Minat masyakat terhadap kegiatan skor 4,9 kriteria baik, Kepuasan kegiatan skor 5 berada pada kriteria baik sekali. Hasil analisis penilaian pelaksanaan kegiatan PKM oleh peserta disajikan melalui Tabel 1.

Tabel 1. Hasil penilaian pelaksanaan kegiatan

\begin{tabular}{|c|c|c|c|}
\hline No & Uraian & Skor & Kriteria \\
\hline 1 & Materi yang disampaikan dalam PKM & 4,9 & Baik \\
\hline 2 & Respon masyarakat terhadap materi yang disampaikan & 4,8 & Baik \\
\hline 3 & Hubungan materi yang disajikan dengan kebutuhan masyarakat & 5,8 & Baik sekali \\
\hline 4 & Keterkaitan antara materi dengan aplikasi yang dapat di serap di masyarakat & 4,7 & Baik \\
\hline 5 & Keterkaitan materi dengan kebutuhan & 4,9 & Baik \\
\hline 6 & Pemateri dan teknik penyajian & 4,8 & Baik \\
\hline 7 & Waktu yang digunakan dalam pemberian materi & 4,6 & Baik \\
\hline 8 & Kejelasan materi & 4,9 & Baik \\
\hline 9 & Minat masyarakat terhadap kegiatan & 4.9 & Baik \\
\hline 10 & Kepuasan kegiatan & 5 & Baik sekali \\
\hline
\end{tabular}

Hasil penilaian kegiatan keseluruhan pelaksanaan PKM menunjukkan rerata skor 4,93 hal ini berarti kegiatan pelaksanaan berada pada kriteria baik. Kegiatan pengabdian ini menunjukkan bahwa terjadi peningkatkan kemampuan guru-guru MGMP Biologi Kabupaten Enrekang terkait pembuatan E-book berbasis Android.

Kegiatan PKM ini dilakukan untuk memberikan kontribusi dalam peningkatan kemampuan guru dalam mengelola proses pembelajaran, sebab tridharma PT mengamanahkan perlunya kegiatan pengandian yang dilakukan dosen sebagai bentuk perhatian dari perguruan tinggi bagi sekolah (Saraswati \& Budiman, 2020). Ada beragam permasalahan yang dihadapi guru dalam pembelajaran, sehingga dibutuhkan upaya pemecahan, salah satu bentuk upaya dimaksud adalah pemberdayaan atau penguatan kemampuan guru (Hudha \& Husamah, 2019; Husamah, Hudha, \& Pantiwati, 2018).

Kegiatan ini tidak dapat berdiri sendiri dan masih membutuhkan kegiatan-kegiatan lanjutan agar dapat memberikan dampak yang signifikan bagi peningkatan kualitas pembelajaran dengan memanfaatkan teknologi informasi dan komunikasi sehingga penerapan TPACK bisa diintegrasikan pada perangkat dan pelaksanaan pembelajaran. Hal ini sejalan dengan Yayuk dan Prastiyowati (2019) bahwa kegiatan Pendampingan terhadap guru perlu dilakukan secara lebih intensif agar kemampuan guru dapat terpenuhi yang diharapkan. Diperlukan juga waktu diskusi yang lebih panjang sehingga dapat memperkaya wawasan guru dalam topik yang disepakati atau menjadi fokus pengabdian.

Beberapa kendala yang dihadapi tim pengabdi selama pelaksanaan program PKM adalah sebagai berikut: (a) pada kegiatan pelatihan, infrastruktur yang dimiliki oleh guru-guru beberapa di antaranya kurang mendukung karena tidak kompatibel dengan software yang digunakan. (b) Penguasaan dan kemampuan dasar yang dimiliki oleh guru-guru dalam memanfaatkan teknologi informasi sangat beragam sehingga pelaksanaan praktek menjadi lebih lambat dari yang direncanakan. (c) Beberapa guru mengeluhkan dukungan sekolah, pemerintah dan fasilitas yang dimiliki oleh siswa masih beragam sehingga kurang mendukung dalam pemanfaatan e-book berbasis android pada proses pembelajaran dan berdampak pada motivasi untuk mengimplementasikan hasil kegiatan pelatihan ini masih sangat rendah. Tim berusaha meyakinkan bahwa implementasi bisa dilakukan secara bertahap dengan memanfaatkan fasilitas yang ada dan dimiliki sebagian besar siswa SMA. Hal ini sejalan dengan Wibowo (2015) bahwa semua guru harus tetap saling mendukung pelaksanaan pembelajaran, saling membantu, semangat, kreatif, dan bekerjasama meskipun dalam kondisi yang penuh dengan keterbatasan sebagai upaya peningkatan kualitas pembelajaran.

\section{KESIMPULAN}

Hasil kegiatan pengabdian ini menunjukkan bahwa terjadi peningkatkan kemampuan guru-guru MGMP Biologi Kabupaten Enrekang tentang pembuatan E-book berbasis Android. Penilaian pelaksanaan kegiatan program kemitraan masyarakat ini diperoleh rerata skor keseluruhan 4,93 (dengan kriteria baik). Berdasarkan hasil pengabdian ini diharapkan dapat menjadi bahan masukan bagi dinas Pendidikan Kabupaten Enrekang pada khususnya, praktisi pendidikan dan pemerintah pada umumnya perlu upaya peningkatan kemampuan guru-guru terkait pengaplikasian teknologi dan informasi pada kegiatan pembelajaran sehingga TPACK (Technological, Pedagogical, Content Knowledge) bisa diintegrasikan pada perangkat dan pelaksanaan pembelajaran.

\section{UCAPAN TERIMA KASIH}

Ucapan Terima Kasih kepada Rektor Universitas Negeri Makassar yang telah memberikan hibah Program Kemitraan Masyarakat PNBP Fakultas UNM. Selanjutnya ucapan terima terima kasih Ketua Lembaga Penelitian dan Pengabdian 
UNM, Direktur Program Pascasarjana UNM dan Dinas Pendidikan Kabupaten Enrekang beserta Guru-guru MGMP Biologi Kabupaten Enrekang yang telah memfasilitasi kegiatan ini.

\section{REFERENSI}

Adnan, A., Muharram, M., \& Jihadi, A. (2019). Pengembangan e-book biologi berbasis konstruktivistik untuk meningkatkan motivasi belajar siswa SMA Kelas XI. Indonesian Journal of Educational Studies (IJES), 22(1), 43-50. https://doi.org/10.26858/ijes.v22i2.11773

Afrianto, A. (2018). Being a professional teacher in the era of industrial revolution 4.0: opportunities, challenges and strategies for innovative classroom practices. English Language Teaching and Research, 2(1), 1-13.

Alisjahbana, A. S., Yusuf, A. A., Anna, Z., Hadisoemarto, P. F., Kadarisman, A., Maulana, N., ... Megananda, M. (2018). Menyongsong SDGs: Kesiapan daerah-daerah di Indonesia. Bandung: Unpad Press.

Anagün, Ş. S. (2018). Teachers' perceptions about the relationship between 21st century skills and managing constructivist learning environments. International Journal of Instruction, 11(4), 825-840. https://doi.org/10.12973/iji.2018.11452a

Ariyana, Y. (2018). TPACK framework. Retrieved July 1, 2020, from PPPPTK IPA website: https://p4tkipa.kemdikbud.go.id/blog/index.php/2018/06/28/tpack-framework/

Badan Pusat Statistik. (2014). Kajian indikator Sustainable Development Goals ( SDGs ). In Badan Pusat Statistik. Jakarta: Badan Pusat Statistik.

Budiarti, A., Handhika, J., \& Kartikawati, S. (2017). Pengaruh model discovery learning dengan pendekatan scientific berbasis e-book pada materi rangkaian induktor terhadap hasil belajar siswa. Jupiter (Jurnal Pendidikan Teknik Elektro), 2(2), 21-28. https://doi.org/10.25273/jupiter.v2i2.1795

Darlen, R. F., Sjarkawi, S., \& Lukman, A. (2015). Pengembangan e-book interaktif untuk pembelajaran fisika SMP. Jurnal Tekno-Pedagogi, 5(1), 13-23. Retrieved from https://online-journal.unja.ac.id/pedagogi/article/view/2282/1618

Hakim, M., \& Hasbiyati, H. (2018). Upaya peningkatan akivitas dan hasil belajar siswa melalui media e-book Berekstensi epub pada materi pencemaran lingkungan di SMP 01 Islam Jember. Jurnal Educazione: Jurnal Pendidikan, Pembelajaran Dan Bimbingan Dan Konseling, 6(1), 55-61. Retrieved from http://ejurnal.uij.ac.id/index.php/EDU/article/view/579

Hala, Y., \& Arifin, A. N. (2019). Pelatihan pembuatan e-book pada Guru IPA MGMP Kabupaten Gowa. Prosiding Seminar Nasional, 602-604. Retrieved from https://ojs.unm.ac.id/semnaslpm/article/view/7988/4643

Hudha, A. M., \& Husamah, H. (2019). Pendampingan implementasi model pembelajaran OIDDE untuk meningkatkan keterampilan pembelajaran berorientasi etika di MA Muhammadiyah 1 Plus Malang. International Journal of Community Service Learning, 3(3), 109-115. https://doi.org/10.23887/ijcsl.v3i3.18635

Husamah, H., Hudha, A. M., \& Pantiwati, Y. (2018). Pendampingan guru SMPN 8 Kota Malang dalam mengembangkan perilaku etis siswa berbasis model pembelajaran OIDDE. International Journal of Community Service Learning, 2(2), 41-50. https://doi.org/10.23887/ijcsl.v2i2.14185

Irodah, P. A., Khoiriyah, H., Batul, Z., Maulidasilvi, R., Setyawan, D., \& Nyono, N. (2020). Revolusi Industri 4 . 0 : Tranformasi Media belajar e-learning menggunakan framework. Prosiding Seminar Nasional V 2019, 368-377. Malang: Pendidikan Biologi FKIP UMM.

Kusumastuti, F. A. (2020). Pengaruh integrasi e-book interaktif pada kegiatan belajar mengajar sains. Jurnal BECOSS (Business Economic, Communication, and Social Sciences), 2(1), 83-88. Retrieved from https://journal.binus.ac.id/index.php/BECOSS/article/view/6063/3738

Oke, A., \& Fernandes, F. A. P. (2020). Innovations in teaching and learning: Exploring the perceptions of the education sector on the 4th industrial revolution (4IR). Journal of Open Innovation: Technology, Market, and Complexity, 6(31), 1-22. https://doi.org/10.3390/JOITMC6020031

Restiyani, R., Juanengsih, N., \& Herlanti, Y. (2015). Profil pemanfaatan teknologi informasi dan komunikasi (TIK) sebagai media dan sumber pembelajaran oleh guru biologi. Edusains, 6(1), 49-66. https://doi.org/10.15408/es.v6i1.1100

Restiyowati, I., \& Sanjaya, I. G. M. (2012). Keywords: learning resources, interactive ebook Abstrak : Unesa Journal of Chemical Education, 1(1), 130-135.

Ritonga, N. (2017). Analisis penggunaan media berbasis teknologi informasi dan komunikasi dalam proses pembelajaran biologi di SMP Negeri Se-Kec. Medan Kota. Cahaya Pendidikan, 3(1), 78-87. https://doi.org/10.33373/chypend.v3i1.872

Saraswati, E., \& Budiman, A. (2020). Instruction of poetry writing in normal students and students with special needs through readers' response and cultural studies approach. Journal of Community Service and Empowerment, 1(1), 46-53. https://doi.org/10.22219/jcse.v1i1.11512

Sharma, P. (2019). Digital revolution of education 4.0. International Journal of Engineering and Advanced Technology, 9(2), 3558-3564. https://doi.org/10.35940/ijeat.a1293.129219

Soulissa, S. M., Smith, A., \& Matdoan, M. N. (2020). Hubungan bahan ajar ebook berbasis android dan berpikir kritis 
konsep sistem pernapasan manusia terhadap hasil belajar siswa kelas VIII SMP Negeri 3 Bula. Biopendix Jurnal Biologi, Pendidikan, dan Terapan, 6(2), 109-116. https://doi.org/10.30598/biopendixvol6issue2page109-116 Suryani, W., \& Sukarmin, S. (2012). Pengembangan e-book interaktif pada materi pokok elektrokimia kelas XII SMA. Unesa Journal Of Chemical Education, 1(2), 54-62. Retrieved from http://jurnalmahasiswa.unesa.ac.id/index.php/journal-of-chemical-education/article/download/343/265

Taguma, M., Feron, E., \& Lim, M. H. (2018). Future of education and skills 2030: Conceptual learning framework. https://doi.org/10.1145/3132847.3132886

Trilling, B., \& Fadel, C. (2009). 21st century skills: Learning for life in our iimes. San Francisco, CA: Jossey-Bass.

Wibowo, C. H. (2015). Problematika profesi guru dan solusinya bagi peningkatan kualitas pendidikan di MTs. Negeri Nguntoronadi Kabupaten Wonogiri (IAIN Surakarta). Retrieved from https://media.neliti.com/media/publications/146215-ID-pentingnya-profesionalisme-guru-dalam-me.pdf

Yayuk, E., \& Prastiyowati, S. (2019). Pendampingan pembuatan perangkat pembelajaran Kurikulum 2013. International Journal of Community Service Learning, 3(4), 222-232. https://doi.org/10.23887/ijcsl.v3i4.21793

Zalsalina, R., Palupi, G., \& Riyaningsih, D. (2020). Penilaian keterampilan abad ke-21. Prosiding Seminar Nasional V 2019, 340-346. Malang: Pendidikan Biologi FKIP Universitas Muhammadiyah Malang. 